Check for updates

Cite this: RSC Adv., 2018, 8, 21288

Received 2nd May 2018

Accepted 26th May 2018

DOI: $10.1039 / c 8 r a 03757 d$

rsc.li/rsc-advances

\section{Transition metal free, late-stage, regiospecific, aromatic fluorination on a preparative scale using a KF/crypt-222 complex $\dagger$}

\author{
Jimmy Erik Jakobsson (D) *a and Patrick Johannes Riss ${ }^{\text {abc }}$
}

Fluorinated organic molecules are of importance in crop protection and materials science and as pharmaceuticals due to their unique properties. Aryl fluorides are of particular interest in medicinal chemistry ${ }^{1}$ due to their exceptional metabolic stability. For instance, fluorine is often used as a tool in medicinal chemistry for fine tuning the physicochemical properties of drug candidates in late stage development. ${ }^{2}$ The presence of fluorine in drug molecules also allows for further investigation by positron emission tomography (PET) via incorporation of radioactive fluorine-18 $\left({ }^{18} \mathrm{~F}, t_{1 / 2}=110 \mathrm{~min}\right)$. The radionuclide ${ }^{18} \mathrm{~F}$ is ideal for PET imaging, due to its very advantageous half-life and decay characteristics. ${ }^{3}$

Current late stage fluorination methodologies of arenes and heteroarenes are often based on expensive, potentially toxic transition-metals $\left(\mathrm{Ag} / \mathrm{Cu},{ }^{4} \mathrm{Cu},{ }^{5} \mathrm{Ni},{ }^{6} \mathrm{Pd}^{7}\right)$ or involve electrophilic fluorination reagents and may necessitate the use of additional, advanced equipment such as gloveboxes to achieve more anhydrous conditions. Therefore a mild, versatile and selective fluorination methodology that utilises cheap nucleophilic fluoride for late stage formation of fluoroarenes is highly sought after. $^{8}$ In addition, we aim to progress into greener, more environmentally friendly alternatives with easy to handle chemicals by moving away from toxic transition metals. In order to be independent from classical substrates of the $S_{N} A r$ reaction, we chose hypervalent iodine species as fluorination precursors. The hypervalent iodine chemistry utilises the plethora of well-investigated and described iodination protocols and iodonium ylide forming reactions as a basis for constructing aryl fluorides. Such a method would also bridge the gap

${ }^{a}$ Realomics Strategic Research Initiative, Department of Chemistry, Faculty for Mathematics and Natural Sciences, University of Oslo, Norway. E-mail: j.e. jakobsson@kjemi.uio.no

${ }^{b}$ Department of Surgery and Neuroscience, OUS-Rikshospitalet HF, Oslo, Norway ${ }^{c}$ Norwegian Medical Cyclotron AS, Nydalen, Oslo, Norway

$\dagger$ Electronic supplementary information (ESI) available. See DOI: $10.1039 / \mathrm{c} 8 \mathrm{ra03757d}$ between preparative organic chemistry and radiochemistry thus applying the same precursor for synthesising both radiotracer and reference compound in the last step (Scheme 1). Radiofluorination of iodonium ylides is well described, ${ }^{9}$ however in radiochemistry reagent stoichiometry is vastly different with the precursor used in $>1000$ fold excess over no carrier added fluorine-18, the limiting reagent.t For the methodology to be useful on preparative scale the precursor should ideally be the limiting reagent and a cheap fluorination reagent such as $\mathrm{KF}$, CsF or TBAF used in excess. We therefore employed a reverse translational approach developing a preparative organic protocol for the fluorination reaction under stoichiometric conditions. Through this new protocol, PET chemistry is merged with preparative organic chemistry enabling use of iodonium ylides as versatile fluorination precursors.

Electron deficient substrates can undergo a classical $\mathrm{S}_{\mathrm{N}} \mathrm{Ar}$ reaction ${ }^{10}$ therefore for this investigation we decided to use 2fluoroanisole as model compound since it is both sterically hindered and electron rich and therefore challenging to produce. All reactions were performed without access to glove box using standard equipment and precautions to allow for good reproducibility in between labs. We began by screening the most common nucleophilic fluorination reagents in organic, dipolar aprotic solvents (Table 1).

Caesium fluoride produced mere trace amounts of product (2), possibly owing to its high hygroscopicity and difficulty of excluding moisture (Table 1, entry 1). Tetrabutylammonium fluoride trihydrate yielded a higher conversion $(2,9 \%)$ but also 3 -fluoroanisole (3) as side product (0.6\%) (Table 1, entry 2). We have previously observed that the reaction is moderately sensitive to moisture $^{9 b}$ on radiochemical scale so we

\footnotetext{
$\ddagger$ We found no benefit of adding triphenylphosphane as previously reported, ${ }^{g}{ }^{b}$ we argue that the reason is that the iodonium ylide is slowly reduced by the phosphane, and consumed reagent is a problem in preparative chemistry that is not encountered in radiochemistry where substrate is used in $>\mathbf{1 0 0 0}$ fold excess. ${ }^{31} \mathrm{P}$ NMR show $\mathrm{PPh}_{3} \mathrm{O}$ as minor side product, ESI. $\dagger$
} 
Reference<smiles>[Te]c1ccccc1</smiles>
This work Precursor

$$
\text { PET tracer }
$$$$
I^{I I I}=L^{\text {Aux }}
$$$$
\stackrel{19}{\stackrel{19}{F^{-}}}
$$$$
\text { R }
$$$$
\stackrel{{ }^{18} \mathrm{~F}^{-}}{\longrightarrow}
$$$$
\text { stoichiometric }{ }^{19} \mathrm{~F}^{-} \quad \text { traces of }{ }^{18} \mathrm{~F}^{-}
$$

Scheme 1 Illustrate a back-translational approach, developing an organic chemistry protocol for synthesising reference compound on preparative scale.

synthesised the anhydrous $\operatorname{TBAF}(t-\mathrm{BuOH})_{4}$ complex, ${ }^{11}$ which although it increased the yield fourfold (Table 1, entry 2) also produced more of the undesired constitutional isomer that would render purification considerably more difficult (Table 1 entry 3). Heating the reaction mixture for a longer time made no difference (Table 1, entry 4) meaning that the constitutional isomer formation is unrelated to product degradation, varying the temperature did not resolve the selectivity problem either (ESI $\dagger$ ). Earlier literature reports suggest that fluorination of aryl bromides goes through an aryne intermediate when using the very basic tetraalkylammonium fluorides ${ }^{12}$ in DMSO as well as radiofluorination of iodonium ylides using $\mathrm{KF} /$ crypt-222 in MeCN. ${ }^{9 a}$ We assumed that since reagent basicity is solvent dependent choosing another solvent could circumvent the problem. However, we found that use of either propylene carbonate or DMSO (Table 1, entries 5 and 6) yielded a comparable ratio of 2-fluoroanisole (2) to 3-fluoroanisole (3) $(11+1 \%$ and $5+1 \%$ respectively) and that the reaction in both chlorobenzene and MeCN (Table 1, entries 7 and 8) proceeded primarily through an aryne intermediate $(12 \%+25 \%$ and $5+$

Table 1 Shows the constitutional isomer distribution as result of

\begin{tabular}{|c|c|c|c|c|}
\hline Entry & Reagent & Solvent & Yield $^{a_{0}} \%(2)$ & Yield $^{a} \%$ (3) \\
\hline 1 & CsF & DMF & Traces & 0 \\
\hline 2 & $\mathrm{TBAF} \cdot 3 \mathrm{H}_{2} \mathrm{O}$ & DMF & $9 \%$ & $0.6 \%$ \\
\hline 3 & $\operatorname{TBAF}(t-\mathrm{BuOH})_{4}$ & DMF & $31 \pm 4 \%$ & $1.4 \pm 0.0 \%$ \\
\hline 4 & $\operatorname{TBAF}(t-\mathrm{BuOH})_{4}$ & $\mathrm{DMF}^{b}$ & $32 \%^{a}$ & $1.4 \%$ \\
\hline 5 & $\operatorname{TBAF}(t-\mathrm{BuOH})_{4}$ & $\mathrm{PC}$ & $11 \%$ & $1 \%$ \\
\hline 6 & $\operatorname{TBAF}(t-\mathrm{BuOH})_{4}$ & DMSO & $5 \%$ & $1 \%$ \\
\hline 7 & $\operatorname{TBAF}(t-\mathrm{BuOH})_{4}$ & $\mathrm{PhCl}$ & $12 \%$ & $25 \%$ \\
\hline 8 & $\operatorname{TBAF}(t-\mathrm{BuOH})_{4}$ & $\mathrm{MeCN}$ & $5 \%$ & $9 \%$ \\
\hline 9 & 1.5 eq. $\operatorname{TBAF}(t-\mathrm{BuOH})_{4}$ & DMF & $30 \pm 0 \%$ & $0.3 \pm 0.1 \%$ \\
\hline 10 & 4 eq. $\operatorname{TBAF}(t-\mathrm{BuOH})_{4}$ & DMF & $5 \pm 0.2 \%$ & $6 \pm 0.2 \%$ \\
\hline
\end{tabular}
varying fluoride source and solvent

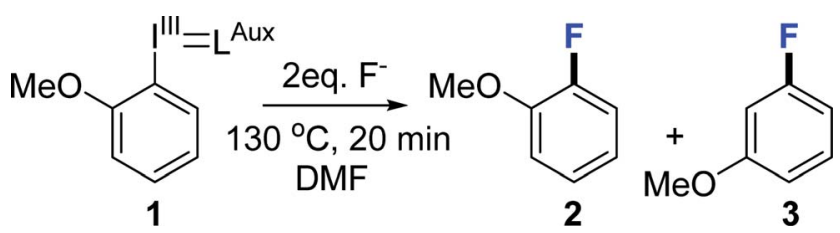

${ }^{a}{ }^{19} \mathrm{~F}$ NMR yield using 4 -fluorobiphenyl as internal standard. Standard deviation is given for reactions performed in duplicate. Product identities were confirmed from spiking with reference compound.

${ }^{b} 1 \mathrm{~h}$ reaction time. $\mathrm{PC}=$ propylene carbonate.

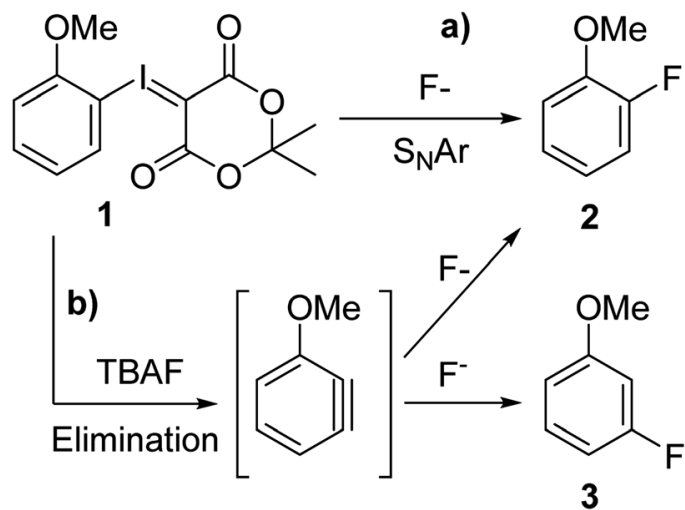

Scheme 2 Shows two competing reaction pathways for fluorination of 1 using $\operatorname{TBAF}(\mathrm{tBuOH})_{4}$. (a) Nucleophilic substitution, (b) TBAF mediated aryne formation and subsequent fluorination yielding both 2 and 3 .

9\% respectively). We concluded that we have two competing reaction pathways and that the aryne intermediate formation is facilitated by TBAF (Scheme 2). By reducing the equivalents of $\operatorname{TBAF}(t-\mathrm{BuOH})_{4}$ from 2 to $\mathbf{1}$ the yield was marginally decreased to $30 \%$ but the formation of 3 -fluoroanisole (3) reduced by three quarters to $0.3 \pm 0.1 \%$ (Table 1 , entry 9 ). This finding suggest that use of tetraalkylammonium fluorides in radiofluorination reactions does not suffer from formation of constitutional isomers since only trace quantities of fluoride is used, which is in agreement with Rotstein et. al. ${ }^{9 c}$ By increasing the equivalents of $\mathrm{TBAF}(t-\mathrm{BuOH})_{4}$ complex to 4 equivalents, $5 \%$ desired 2 -fluoroanisole (2) and 6\% undesired 3-fluoroanisole (3) (Table 1 entry 10) were obtained, further supporting our hypothesis.

With this finding, we decided to move away from tetraalkylammonium fluorides and investigate metal fluorides in combination with phase transfer catalysts (Table 2) to enhance both solubility and nucleophilicity.

Addition of conventional phase transfer catalyst potassium complexing crown ether 18-crown-6 to KF produced only traces of product (Table 2, entry 1). Surprisingly neither CsF nor KF in combination with cryptand crypt-222 produced satisfactory results, $1 \pm 1 \%$ and $8 \pm 2 \%$ of 2 -fluoroanisole (2) respectively (Table 2, entries 2 and 3) but with a ${ }^{19} \mathrm{~F}$ NMR spectrum devoid of the 3-fluoroanisole signal (3). We hypothesised that the limited solubility of potassium fluoride ${ }^{13}$ in DMF made formation of $\mathrm{KF} /$ crypt-222 complex too slow to allow for an efficient fluorination reaction since the iodonium ylide substrate slowly degrade under the fluorination conditions. ${ }^{9 b}{ }^{13} \mathrm{C}-\mathrm{NMR}$ shows only partial formation of crypt-222/ $\mathrm{K}^{+}$complex after 2 hours of heating $\mathrm{KF}$ and crypt-222 in DMF at $130{ }^{\circ} \mathrm{C}$ (ESI $\dagger$ ) strengthening our hypothesis. Adding water to the reaction mixture to facilitate KF/crypt-222 complex formation would destroy the substrate and strongly diminish the nucleophilicity of fluoride. Therefore, we anticipated that the fluorination complex need to be formed in advance. We made the KF/crypt-222 complex from a solution of $\mathrm{MeCN} / \mathrm{H}_{2} \mathrm{O}$ adding $33 \mathrm{~mol} \% \mathrm{~K}_{2} \mathrm{CO}_{3}$ to hinder evaporation of $\mathrm{HF}$. The complex was thoroughly dried for several days under high vacuum. In line with our hypothesis, the pre-formed KF/crypt-222 complex produced a significantly 
Table 2 Shows the constitutional isomer distribution as result of varying fluoride source and solvent. Reaction performed on $1(1.9 \mathrm{mg}$, $5 \mu \mathrm{mol})$ and fluorination reagent $(10 \mu \mathrm{mol})$ in $\mathrm{DMF}(0.5 \mathrm{ml})$ at $130^{\circ} \mathrm{C}$ for $20 \mathrm{~min}$

\begin{tabular}{llll}
\hline Entry & Reagent & Yield $^{a} \%(2)$ & Yield $^{a} \%(3)$ \\
\hline 1 & KF/18C6 & $1 \pm 0 \%$ & 0 \\
2 & CsF/crypt-222 & $1 \pm 1 \%$ & 0 \\
3 & KF/crypt-222 & $8 \pm 2 \%$ & 0 \\
4 & KF/crypt-222 & $46 \pm 2 \%^{b}$ & 0 \\
5 & 1.5 eq. KF/crypt-222 & $36 \%^{b}$ & 0 \\
6 & 4 eq. KF/crypt-222 & $43 \%^{b}$ & 0
\end{tabular}

${ }^{a}{ }^{19} \mathrm{~F}$ NMR yield using 4-fluorobiphenyl as internal standard. Where standard deviation is given, the reaction was performed in duplicate. Product identities were confirmed from spiking with reference compound. ${ }^{b}$ Preformed KF/crypt-222 complex containing $33 \mathrm{~mol} \%$ $\mathrm{K}_{2} \mathrm{CO}_{3}$ to avoid formation of $\mathrm{HF}$ during drying of $\mathrm{KF} /$ crypt-222 complex. Crypt-222 = 4,7,13,16,21,24-hexaoxa-1,10-diazabicyclo[8.8.8] hexacosane.

higher yield (46 $\pm 2 \%$ ) gratefully without formation of any constitutional isomers (Table 2, entry 4). The pre-made $\mathrm{KF} /$ crypt-222 complex is not visibly hygroscopic and is an easy to weigh free flowing powder (ESI $\dagger$ ) that can be stored for at least several weeks in a closed vial at room temperature without any impairment of the fluorination yield. Increasing or reducing the equivalents of $\mathrm{KF} /$ crypt-222 complex did not improve the yield further (Table 2, entries 5 and 6). The complex readily dissolves in DMF and ${ }^{13} \mathrm{C}$-NMR gives three new signals upfield of the host crypt-222.

With the optimised fluorination conditions in hand, we sat out to screen a range of substrates to examine the reaction scope (Fig. 1). 4-Fluoroanisole (4) was produced in a significantly lower yield $(10 \pm 1 \%)$ than 2-fluoroanisole $(2,46 \pm 2 \%)$, the large difference is likely due to the substrate being both deactivated and lacking an ortho-substituent thus not benefitting from the ortho-effect. ${ }^{14}$ Fluorination of non-activated substrates produced fluorobenzene (5) and 4-chloro-1-fluorobenzene (6) in modest yields ( $33 \pm 2 \%$ and $26 \pm 4 \%$ ) but good enough to be useful for synthesising sufficient material of reference compounds where milligram quantities is sufficient. Fluorination constructing 5-fluoro- $m$-xylene (7) proceeded in an acceptable yield (36 $\pm 1 \%$ ) whereas sterically hindered constitutional isomer 2-fluoro- $m$-xylene (8) was produced in a high yield (78 \pm $7 \%$ ) demonstrating the benefit of ortho-substitution. Activated substrates 4-fluorodimethylbenzamide (9) and 4-fluorobenzonitrile (10) were as expected obtained in high to excellent yields $(70 \pm 3 \%$ and $52 \pm 18 \%)$ albeit under milder conditions then used for $\mathrm{S}_{\mathrm{N}} \mathrm{Ar}$-fluorinations. Activated drug compound tropane (11) was produced in near quantitative yield ( $88 \pm 7 \%)(90 \%$ isolated yield) and the challenging to access morphinane (12) fluorinated well in $30 \pm 1 \%(20 \%$ isolated yield), sufficient for testing its potential use as an NMDA-PET radioligand. The radiotracer $\left[{ }^{18} \mathrm{~F}\right] \mathbf{1 2}$ was synthesised in $38 \%$ isolated yield ( $150 \mathrm{MBq}>95 \% \mathrm{RCP}$ after cartridge purification). Activated tropane was readily fluorinated in room temperature yielding $33 \%$ of 11 . Encouraged by the positive results we decided to investigate how well the pre-dried KF/crypt-222

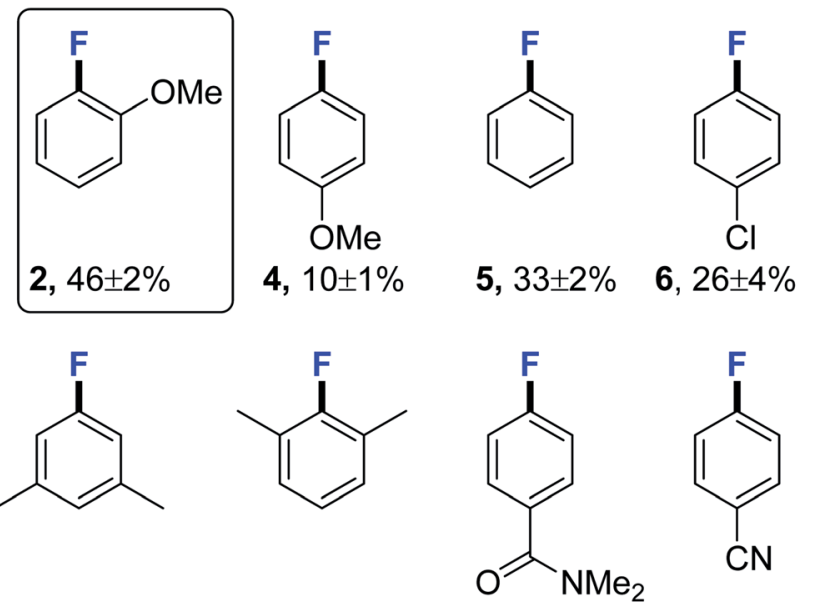

$7,36 \pm 1 \% \quad 8,78 \pm 7 \% \quad 9,70 \pm 3 \% \quad 10,52 \pm 18 \%$<smiles>CN1C2CCC1CC(OC(=O)c1ccc(F)cc1)C2</smiles><smiles>COc1cc2c(cc1F)C[C@H]1C[C@]23CCCC[C@@H]3N1C=O</smiles>

$11,88 \pm 7 \%\left(90 \%{ }^{\mathrm{a}}\right)$
$33 \%($ r.t. $1 \mathrm{~h})$
$34 \%\left(\mathrm{NO}_{2}->\mathrm{F}\right)$

12, $30 \pm 1 \%\left(20 \%{ }^{\mathrm{a}}\right)$

RCY $68 \%\left(38 \%{ }^{b}\right)$

Fig. 1 Fluorination substrate scope under the developed conditions. ${ }^{19} \mathrm{~F}$ NMR yields using 4-fluorobiphenyl as internal standard. Where standard deviation is given, the reaction was performed in duplicate. Product identities were confirmed from spiking with reference compound. Reaction performed on ylide $(5 \mu \mathrm{mol})$ and crypt-222/KF/ $\mathrm{K}_{2} \mathrm{CO}_{3}(4: 3: 1)(6.6 \mathrm{mg}, 10 \mu \mathrm{mol}$ of $\mathrm{KF})$ in DMF $(0.5 \mathrm{ml})$ at $130{ }^{\circ} \mathrm{C}$ for $20 \mathrm{~min}$. Radiofluorination performed using ylide (3.7 $\mu \mathrm{mol})$, crypt-222 ( $5 \mathrm{mg}, 13 \mu \mathrm{mol}) \mathrm{K}_{2} \mathrm{CO}_{3}(0.92 \mathrm{mg}, 5.5 \mu \mathrm{mol})$ and ${ }^{18} \mathrm{~F}^{-}(400 \mathrm{MBq})$ in DMF $(0.5 \mathrm{ml})$ at $130^{\circ} \mathrm{C}$ for $20 \mathrm{~min}$. Isolated yield using tracer principle after cartridge purification ( $\mathrm{C}_{18}$ and $\left.\mathrm{Si}\right) .{ }^{\mathrm{b}} \mathrm{Non}$-decay corrected isolated yield after cartridge purification $\left(\mathrm{C}_{18}\right.$ and $\left.\mathrm{Si}\right)$ in $>95 \% \mathrm{RCP}$. $\mathrm{RCY}=$ radiochemical yield. Crypt-222 = 4,7,13,16,21,24-hexaoxa-1,10-diazabicyclo[8.8.8] hexacosane. Entry for 2 is identical to Table 2 entry 4.

complex fluorinated activated nitro arenes. We synthesised the $\mathrm{NO}_{2}$-precursor of (11) for a direct comparison and attempted fluorination under standard conditions obtaining 11 in 34\% yield compared to $88 \pm 7 \%$ when using the iodonium ylide precursor. Fluorination at room temperature produced only traces of product after 1 hour (ESI $\dagger$ ).

A transition metal free fluorination method based on an anhydrous fluorine complex and iodonium ylides useful for preparative aromatic fluorination reactions is successfully demonstrated. Merging radiochemistry and conventional organic chemistry by employing the same precursor eliminates the need of additional synthetic work. An additional advantage of using a transition metal free methodology is to avoid possible interference during biological characterisation and during 
translation into clinical radiochemistry. We successfully demonstrate the use of the methodology by synthesising complex derivatives via a late stage fluorination reaction and the radioactive counterparts from the same precursor. The method is a good compliment to existing methodologies and with high yield reproducibility expands the accessible chemical space of fluorinated drug molecules.

\section{Conflicts of interest}

There are no conflicts of interest to declare.

\section{Acknowledgements}

This work was partly supported by the Research Council of Norway through the Norwegian NMR Platform, NNP (226244/ F50) and a personal grant to PJR (NFR ES 231553) JJ thanks the Realomics SRI for a doctoral fellowship.

\section{Notes and references}

1 (a) J. Wang, M. Sanchez-Rosello, J. L. Acena, C. del Pozo, A. E. Sorochinsky, S. Fustero, V. A. Soloshonok and H. Liu, Chem. Rev., 2014, 114, 2432-2506; (b) Y. Zhou, J. Wang, Z. Gu, S. Wang, W. Zhu, J. L. Acena, V. A. Soloshonok, K. Izawa and H. Liu, Chem. Rev., 2016, 116, 422-518.

2 E. P. Gillis, K. J. Eastman, M. D. Hill, D. J. Donnelly and N. A. Meanwell, J. Med. Chem., 2015, 58, 8315-8359.

3 (a) P. W. Miller, N. J. Long, R. Vilar and A. D. Gee, Angew. Chem., Int. Ed. Engl., 2008, 47, 8998-9033; (b) S. Preshlock,
M. Tredwell and V. Gouverneur, Chem. Rev., 2016, 116, 719-766.

4 P. S. Fier and J. F. Hartwig, J. Am. Chem. Soc., 2012, 134, 10795-10798.

5 (a) N. Ichiishi, A. J. Canty, B. F. Yates and M. S. Sanford, Org. Lett., 2013, 15, 5134-5137; (b) P. S. Fier, J. Luo and J. F. Hartwig, J. Am. Chem. Soc., 2013, 135, 2552-2559.

6 H. Lee, J. Borgel and T. Ritter, Angew. Chem., Int. Ed. Engl., 2017, 56, 6966-6969.

7 H. G. Lee, P. J. Milner and S. L. Buchwald, J. Am. Chem. Soc., 2014, 136, 3792-3795.

8 M. G. Campbell and T. Ritter, Chem. Rev., 2015, 115, 612-633.

9 (a) J. Cardinale, J. Ermert, S. Humpert and H. H. Coenen, RSC Adv., 2014, 4, 17293-17299; (b) J. E. Jakobsson, G. Gronnevik and P. J. Riss, Chem. Commun., 2017, 53, 12906-12909; (c) B. H. Rotstein, N. A. Stephenson, N. Vasdev and S. H. Liang, Nat. Commun., 2014, 5, 4365.

10 D. J. Adams and J. H. Clark, Chem. Soc. Rev., 1999, 28, 225231.

11 D. W. Kim, H. J. Jeong, S. T. Lim and M. H. Sohn, Angew. Chem., Int. Ed., 2008, 47, 8404-8406.

12 V. V. Grushin and W. J. Marshall, Organometallics, 2008, 27, 4825-4828.

13 D. A. Wynn, M. M. Roth and B. D. Pollard, Talanta, 1984, 31, 1036-1040.

14 B. H. Rotstein, L. Wang, R. Y. Liu, J. Patteson, E. E. Kwan, N. Vasdev and S. H. Liang, Chem. Sci., 2016, 7, 4407-4417. 